\title{
Effects of Triterpenoid-Rich Extracts of Ganoderma tsugae on Airway Hyperreactivity and Th2 Responses in vivo
}

\author{
Miaw-Ling Chen Bi-Fong Lin \\ Department of Biochemical Science and Technology, Institute of Microbiology and Biochemistry, \\ College of Life Science, National Taiwan University, Taipei, Taiwan, ROC
}

\section{Key Words}

Ganoderma tsugae $\cdot$ Triterpenoids • Asthma $\cdot$ Th2 responses • Airway hyperresponsiveness

\begin{abstract}
Background: Airway inflammation and Th2 responses play central roles in allergic asthma. We have previously reported that Ganoderma tsugae supplementation could attenuate airway inflammation in the murine model. Since it remains unclear which part of the $G$. tsugae exerts this effect on allergic asthma in vivo, this study was meant to investigate if triterpenoid extracts have anti-inflammatory effects on airway responses and regulatory effects on Th2 responses. Methods: BALB/c mice sensitized intraperitoneally and challenged with ovalbumin (OVA) were treated with either triterpenoid-rich extracts (TRE) of $G$. tsugae or prednisolone for 2 weeks. The effects of TRE on bronchial airway hyperresponsiveness (AHR), airway inflammation, serum antigenspecific antibody levels, and cytokine secretions from splenocytes were evaluated. Results: TRE supplementation significantly decreased AHR and reduced the total infiltrating leukocytes and eosinophils, as well as the levels of inflammatory mediators, such as interleukin (IL)-4, IL-5 and eotaxin in bronchoalveolar lavage fluid when compared with those of the control group. Lung histology also showed
\end{abstract}

less cell recruitment and lung damage. TRE supplements suppressed IL-5 secretions from OVA-stimulated splenocytes, but did not affect the cell number of splenocytes, which was also reduced by prednisolone. Although OVAspecific immunoglobulin E levels were not significantly different among the groups, a lower level of OVA-specific immunoglobulin G1, another Th2-related antibody, was found in TRE and prednisolone treatment. Conclusions: TRE of G. tsugae exert anti-inflammatory effects on airway responses and attenuate Th2 responses without the overall immunosuppression effects in allergic murine models of asthma.

Copyright $\odot 2007$ S. Karger AG, Basel

\section{Introduction}

Bronchial asthma is a chronic inflammatory disease with many clinical phenotypes. The characteristics of allergic asthma include airway hyperresponsiveness (AHR) and bronchial inflammation through the accumulation of eosinophils, lymphocytes and mast cells in the airway. Murine models of allergic bronchial asthma have been developed to study the pathophysiology of the disease. Mice sensitized and challenged with OVA significantly increase airway inflammation and Th2 responses [1]. The allergic immune responses in asthma arise from an

\section{KARGER}

Fax +4161306 1234

E-Mail karger@karger.ch

www.karger.com (c) 2007 S. Karger AG, Basel

$1018-2438 / 07 / 1431-0021 \$ 23.50 / 0$

Accessible online at:

www.karger.com/iaa
Correspondence to: Prof. Bi-Fong Lin

Department of Biochemical Science and Technology

Institute of Microbiology and Biochemistry, National Taiwan University, No. 1, Sec. 4

Roosevelt Road, Taipei 10617, Taiwan (ROC)

Tel. +88623366 4451, Fax +88622362 1301, E-Mail bifong@ntu.edu.tw 
Fig. 1. Schematic diagram of the experiment protocol. BALB/c mice were sensitized with three intraperitoneal (i.p.) injections of OVA (10, 30 and $30 \mu \mathrm{g} /$ mouse) on days 0,14 and 28 , followed by aerosolized OVA solution $(50 \mathrm{mg} / \mathrm{ml}$ in normal saline). The sensitized mice were grouped by OVA-specific IgE titers on day 43. Triterpenoids and prednisolone were administered to the OVA-sensitized mice for 14 days. Sera were collected for OVA-specific IgE, IgG1 and IgG2a analysis at day 49.

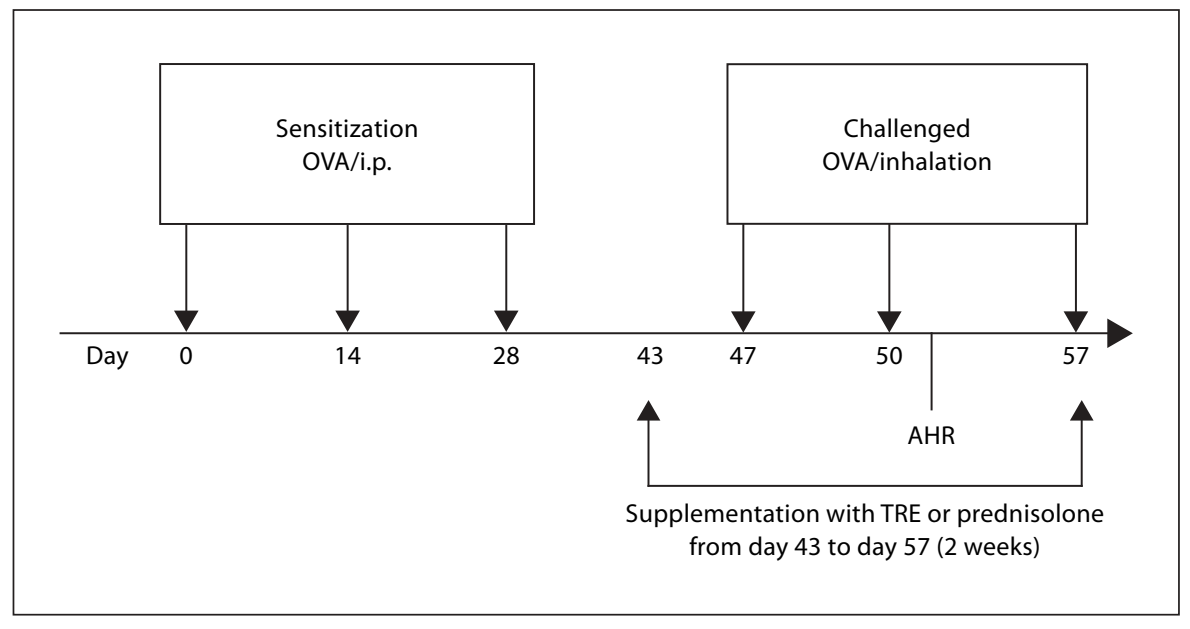

imbalance between Th1 and Th2 cells, and asthmatic inflammation is clearly associated with an increase in Th2 cytokines interleukin (IL)-4, IL-13 and IL-5, which play essential roles in both immunoglobulin (Ig) E production and eosinophilic infiltration [2].

Several studies have suggested that a Chinese herbal formula decreases airway inflammation and antigenspecific IgE levels, as well as modulating Th1/Th2 responses [3-5]. Moreover, all of the proposed herbal formulas contain some amount of Ganoderma, which have been reported to possess both antitumor and immunomodulatory effects [6].

Ganoderma lucidum is the most studied species of the Ganoderma. It is known for many biological activities due to its polysaccharides, oxygenated triterpenoids, and LZ-8 of Ganoderma [6]. Ganoderma tsugae is another commonly used species in Chinese herbal medicine and health food. It has attracted much attention because its polysaccharides have been demonstrated to have antitumor activities $[7,8]$. In our previous studies, the G. tsugae extract increased IL-2 and decreased IL-4 cytokine production from splenocytes of BALB/c mice [9]. Further studies showed that the G. tsugae extract alleviated inflammatory mediator secretion in bronchoalveolar lavage fluid (BALF) of airway-sensitized and challenged $\mathrm{BALB} / \mathrm{c}$ mice [1].

It has also been reported that triterpenoids decrease histamine release from rat peritoneal mast cells [10]. More than 100 species of triterpenoids have been isolated from Ganoderma. Therefore, to investigate if triterpenoids are the effective component, a triterpenoid-rich fraction of $G$. tsugae was applied to treat airway-sensitized and challenged $\mathrm{BALB} / \mathrm{c}$ mice in this study. We re- port here for the first time that triterpenoid-rich extracts (TRE) of Ganoderma attenuate allergen-induced airway inflammation and Th2 responses in vivo.

\section{Materials and Methods}

\section{Materials}

The TRE were provided by the Double Crane Group (YungKien Industry Corp., Taiwan). The TRE fraction was $4.2 \%$, extracted from the fruiting body of G. tsugae YK-01 with acidic ethyl acetate, as previously described [11]. The purity of the TRE was identified by reverse-phase HPLC methods to be $38 \%$ and contained nine major peaks identified as ganoderic acids (ganoderic acids A, B, C, C5, C6, D, E and G, and ganoderenic acid D), reported previously by Chen and Chen [12].

\section{Animal and Experimental Protocol}

Inbred female BALB/c mice (6 weeks old) were purchased from the Animal Center at the National Taiwan University College of Medicine, Taipei, Taiwan, and maintained at the Department of Biochemical Science and Technology at the National Taiwan University. The animal room was kept on a 12-hour light and 12 -hour dark cycle at constant temperature $\left(25 \pm 2{ }^{\circ} \mathrm{C}\right)$ and humidity. The mice were housed individually in stainless steel wire cages and fed on a chow diet (Lab Rodent Chow 5001; Ralson Purina, St. Louis, Mo., USA) to acclimatize for 2 weeks before feeding the experimental diet.

The BALB/c mice ( 8 weeks old) were sensitized and challenged to induce allergic airway inflammation (fig. 1). In brief, mice were sensitized intraperitoneally with ovalbumin (OVA; Sigma, St. Louis, Mo., USA) in alum adjuvant (Imject ${ }^{\circledR}$ Alum; Pierce, Rockford, Ill., USA) three times twice weekly according to our previous study [13]. Nonsensitized control mice received alum only for confirmation of sensitization operation (data not shown). Then, these OVA-sensitized mice were divided by randomization of OVA-specific IgE titers into five groups $(\mathrm{n}=10)$, including a control group, three experimental groups which were fed with 1, 2 
and $5 \mathrm{mg} /$ day TRE of G. tsugae, respectively, and a positive control treated with prednisolone, a steroid anti-inflammatory drug ( $5 \mathrm{mg} / \mathrm{kg}$ body weight; Sigma). During 2 weeks of treatment, OVA-sensitized BALB/c mice were then challenged twice at 3-day intervals by aerosolized OVA at a concentration of 5\% OVA in phosphate-buffered saline (PBS) for $30 \mathrm{~min}$ in a chamber equipped with an ultrasonic nebulizer (Ultra-Neb99; DeVilbiss, Somerset, Pa., USA). Nonsensitized control mice received PBS only. AHR was measured the next day after the second challenge. One week later, the mice received a third challenge and were euthanized by $\mathrm{CO}_{2}$ inhalation. BALF was collected and assayed. Serum and spleen cells were also collected for further analysis of the immune responses.

\section{Determination of $A H R$}

An increase in AHR after methacholine (Sigma) challenge has been demonstrated as a diagnostic sign of asthma in animal models [14]. Twenty-four hours after the secondary OVA inhalation, AHR was measured in mice using whole-body plethysmography (Buxco, Wilmington, N.C., USA). Airway responsiveness was measured by aerosolizing increasing concentrations of methacholine $12.5-50 \mathrm{mg} / \mathrm{ml}$ in PBS, using an AeroSonic ultrasonic nebulizer (DeVilbiss). After each concentration, recordings were taken for $3 \mathrm{~min}$. The enhanced pause (Penh) values measured during each 3-min sequence were expressed as an increase over baseline Penh values following PBS exposure.

\section{Collection of BALF and Cellular Differential Counts}

BALF collection and differential cell counts were manipulated as described by Lin et al. [1]. Briefly, after the mice were euthanized by $\mathrm{CO}_{2}$ inhalation and intubated, their lungs and airways were lavaged with 5 instillations of $0.5 \mathrm{ml}$ sterile saline $(0.9 \%$ $\mathrm{NaCl}$ ) for a total of $2.5 \mathrm{ml}$ through the trachea. Approximately $2.5 \mathrm{ml}$ of BALF was recovered with each sample and the volume did not differ significantly among groups. BALF was centrifuged at $200 \mathrm{~g}$ for $10 \mathrm{~min}$ at $4^{\circ} \mathrm{C}$. The supernatant was collected and kept at $-80^{\circ} \mathrm{C}$ for IL-4, IL-5, eotaxin and prostaglandin $\mathrm{E}_{2}\left(\mathrm{PGE}_{2}\right)$ analysis. The cell pellet was washed and resuspended in $250 \mu \mathrm{l}$ normal saline containing 10\% bovine serum albumin (BSA; Sigma). Total cells were counted with a hemocytometer using the trypan blue dye exclusion method. BALF cells with a concentration of $2 \times 10^{5}$ were cytocentrifuged and then stained with Liu's stain for eosinophil, neutrophil, macrophage and lymphocyte counts. According to the standard morphologic criteria, at least 200 white blood cells were counted, and the total number of each cell type from BALF was calculated.

\section{Lung Histology}

To evaluate the effects of TRE on lung inflammation, after the lavage, the lungs of mice were immediately removed and fixed in $10 \%$ neutral buffered formalin. The lung tissues were subsequently embedded in paraffin and cut into $5-\mu \mathrm{m}$-thick sections. The frozen sections were stained with hematoxylin-eosin, and microscopic images were made with a Leica DMR system (Leica Camera AG, Solms, Germany).

Cytokines and Chemokine Assay of BALF and Splenocytes

Splenocytes with a concentration of $5 \times 10^{6}$ cells $/ \mathrm{ml}$ were set up in 48-well plates in RPMI-1640 medium supplemented with tissue culture medium in the absence or presence of mitogen, such as concavalin A (ConA, $5 \mu \mathrm{g} / \mathrm{ml}$; Sigma) or OVA $(25 \mu \mathrm{g} / \mathrm{ml}$; Sig$\mathrm{ma})$ for $48 \mathrm{~h}$. The cytokine levels in BALF and splenocyte culture supernatants were measured by sandwich ELISA methods [1]. Briefly, the anti-cytokine antibody, including purified rat antimouse cytokine monoclonal antibodies IL-2, interferon (IFN)- $\gamma$, IL-4 and IL-5 (Pharmingen, San Diego, Calif., USA), was coated in the 96-well plates (Nunc, Roskilde, Denmark). After overnight incubation at $4^{\circ} \mathrm{C}$ and having been blocked with PBS containing $1 \%$ BSA for $30 \mathrm{~min}$, the samples and standards (recombinant mouse cytokines; Pharmingen) were added to the 96-well plates for $2 \mathrm{~h}$ of incubation. The biotin-conjugated antibodies (biotinylated rat anti-mouse cytokine monoclonal antibodies; Pharmingen) were added and incubated. After washing, the streptavidinconjugated peroxidase (Pierce) was added for $1 \mathrm{~h}$. The substrates, 2,2'-azino-bis-3-ethyl-benzthiazoline-6-sulfonic acid (ABTS; Sigma), were added to each well for $20 \mathrm{~min}$ to develop color. The plates were read in a microplate autoreader (Microplate autoreader; Bio-Tek Instrument, Inc., Winooski, Vt., USA) at $405 \mathrm{~nm}$. The detection limits for IL-2, IFN- $\gamma$ and IL-5 are $75 \mathrm{pg} / \mathrm{ml}$, and $3.9 \mathrm{pg} / \mathrm{ml}$ for IL-4.

The eotaxin concentration in BALF was determined by mouse eotaxin sandwich ELISA kit (R\&D Systems, Minneapolis, Minn., USA). The eotaxin concentration was assayed according to the manufacturer's instructions. After the color reagent was added, the plate was incubated at room temperature for $20 \mathrm{~min}$ for color development. The absorbance in the microplate was measured at $630 \mathrm{~nm}$ on a plate reader. The eotaxin level in BALF was determined using the standard curve. The detection limit for eotaxin is $3.9 \mathrm{pg} / \mathrm{ml}$.

\section{Determination of $P G E_{2}$ Levels in $B A L F$}

The $\mathrm{PGE}_{2}$ level in BALF was determined by the competitive enzyme immunoassay kit ( $\mathrm{PGE}_{2}$ Enzyme Immunoassay kit; Assay Designs, Inc., Ann Arber, Mich., USA). A monoclonal antibody to $\mathrm{PGE}_{2}$ supplied in the kit was used to bind, in a competitive manner, $\mathrm{PGE}_{2}$ in the sample or $\mathrm{PGE}_{2}$ which conjugated with an alkaline phosphatase molecule. After a simultaneous incubation at room temperature, the excess reagents were washed away and the substrate was added. After a sufficient incubation time, the enzyme reaction was stopped and the yellow color generated was read on a microplate reader at $405 \mathrm{~nm}$. Using the standard curve, the $\mathrm{PGE}_{2}$ concentration for each unknown sample was determined. The detection limit for $\mathrm{PGE}_{2}$ is $39 \mathrm{pg} / \mathrm{ml}$.

\section{Determination of Anti-OVA Antibodies}

Serum anti-OVA IgE, IgG1 and IgG2a antibody titers were measured by the ELISA method, as previously described [13]. Briefly, 96-well plates were coated with $10 \mu \mathrm{g} \mathrm{OVA} / \mathrm{ml} \mathrm{NaHCO}$ buffer $(0.1 \mathrm{M}, \mathrm{pH} 8.2)$. After overnight incubation at $4^{\circ} \mathrm{C}$ and having been blocked with 1\% BSA/PBS buffer for $2 \mathrm{~h}$ at room temperature, the serum samples and positive control serum were appropriately diluted with blocking buffer (1/50 for IgE, 1/500,000 for IgG1, and 1/800 for IgG2a assay, respectively) and added to the 96-well plate. After $2 \mathrm{~h}$ incubation, the plates were washed and biotin-conjugated anti-mouse IgG1, IgG2a and IgE (Pharmingen) were added. After further $2 \mathrm{~h}$ incubation, streptavidin-conjugated peroxidases were likewise added. The enzyme substrate ABTS was added and incubated for $20 \mathrm{~min}$ at room temperature. The antibody levels of the samples were compared with the positive sample. The positive sample was a pool of serum collected from 
Fig. 2. Effect of triterpenoid supplementation on AHR in OVA-sensitized and challenged BALB/c mice after 1 week of supplementation. Twenty-four hours after the second OVA inhalation, the sensitized mice were assessed for methacholine reactivity. The change in Penh values from baseline was determined in response to increasing doses of inhaled methacholine. ${ }^{*} \mathrm{p}<0.05$; significantly different from the control group (Student's t test; $\mathrm{n}=8-9$, mean \pm SEM).

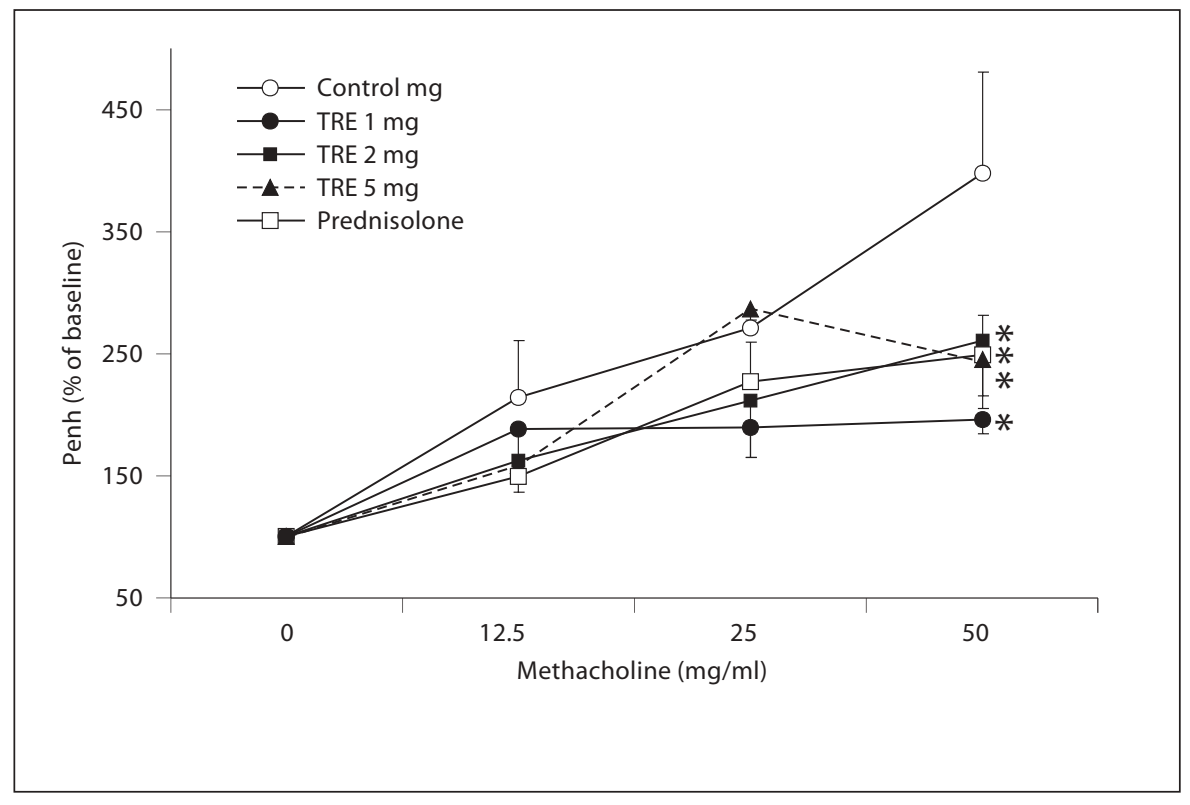

Table 1. Effects of triterpenoid supplementation on cellularity in BALF from OVA-sensitized and challenged $\mathrm{BALB} / \mathrm{c}$ mice

\begin{tabular}{llllll}
\hline \multicolumn{7}{l}{ Cell counts in BALF, $\times 10^{5}$} & & \\
\cline { 2 - 6 } & total cells & eosinophils & monocytes & neutrophils & lymphocytes \\
\hline Control & $38.2 \pm 21.3$ & $3.12 \pm 2.35$ & $3.83 \pm 2.41$ & $9.50 \pm 4.77$ & $21.8 \pm 15.0$ \\
TRE 1 mg & $23.4 \pm 13.1^{*}$ & $1.12 \pm 0.65^{*}$ & $3.41 \pm 1.02$ & $6.42 \pm 3.17^{* *}$ & $14.4 \pm 10.0^{* *}$ \\
TRE 2 mg & $22.0 \pm 8.6^{*}$ & $0.83 \pm 0.40^{*}$ & $3.95 \pm 1.82$ & $6.47 \pm 2.87^{* *}$ & $10.8 \pm 5.1^{*}$ \\
TRE 5 mg & $32.3 \pm 2.6$ & $1.30 \pm 0.98^{*}$ & $5.43 \pm 3.02$ & $8.55 \pm 4.38$ & $17.0 \pm 7.6$ \\
Prednisolone & $5.9 \pm 2.6^{*}$ & $0.21 \pm 0.24^{*}$ & $0.72 \pm 0.67^{*}$ & $1.04 \pm 0.87^{*}$ & $4.0 \pm 1.1^{*}$ \\
\hline
\end{tabular}

BALF was collected $24 \mathrm{~h}$ after the last OVA inhalations. Cytospin preparations were examined for cellular content.

${ }^{*} \mathrm{p}<0.05 ;{ }^{* *} 0.05<\mathrm{p}<0.1$; significantly different from the control group (Student's $\mathrm{t}$ test; $\mathrm{n}=8-10$, mean $\pm \mathrm{SD})$.

OVA-sensitized mice with strong response (optical density $>1$ ). The results of the antibody titer were expressed as ELISA units $(\mathrm{EU}): \mathrm{EU}=\left(\mathrm{A}_{\text {sample }}-\mathrm{A}_{\text {blank }}\right) /\left(\mathrm{A}_{\text {positive }}-\mathrm{A}_{\text {blank }}\right)$.

\section{Statistical Analysis}

The significance of difference among all of the groups was analyzed statistically by unpaired Student's t test of the SAS program system (Strategic Application Software, SAS Windows version 8.2; SAS Institute Inc., Cary, N.C., USA) throughout the study. Data are expressed as mean \pm SD. Differences between the control and other groups were considered statistically significantly if $\mathrm{p}<0.05$.

\section{Results}

\section{TRE Suppressed AHR and Inflammation}

Figure 2 shows AHR to aerosolized methacholine measured $24 \mathrm{~h}$ after the secondary 5\% OVA solution pulmonary challenge. With the increase in methacholine concentration, the Penh values were increased compared with the baseline. Both TRE and prednisolone treatment significantly reduced Penh values when challenged with $50 \mathrm{mg} / \mathrm{ml}$ methacholine.

Airway inflammation is the characteristic of allergic asthma. Cell infiltration, eosinophilia and IL-4, IL-5, eotoxin and $\mathrm{PGE}_{2}$ secretions in BALF are the indicators of 


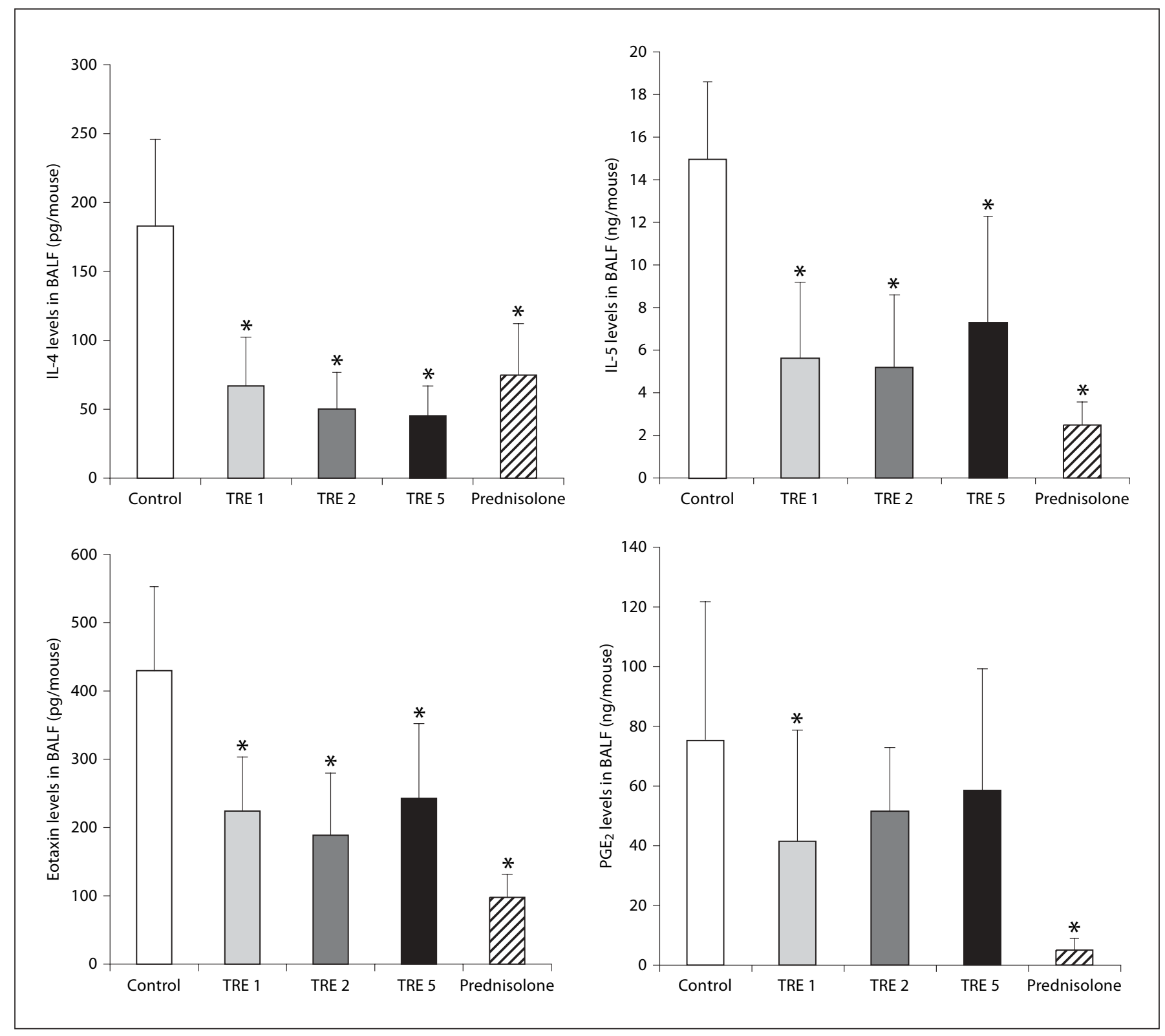

Fig. 3. Effects of triterpenoid supplementation on inflammatory mediators in BALF from OVA-sensitized and challenged BALB/c mice after 2 weeks of supplementation. BALF was collected $24 \mathrm{~h}$ after the last OVA inhalations. The inflammatory mediators in BALF were assayed as described in Materials and Methods, and data were expressed as the total amount in each BALF from each mouse. ${ }^{*} \mathrm{p}<0.05$; significantly different from the control group (Student's t test; $\mathrm{n}=8-10$, mean $\pm \mathrm{SD}$ ).

airway inflammation. As shown in table 1, prednisolone, an anti-inflammatory drug, remarkably decreased cell infiltration in BALF. TRE supplement significantly decreased eosinophil recruitment, but had no significant effect on monocytes. The TRE 1-mg and TRE 2-mg groups also significantly decreased total cell infiltration and tended to decrease $(0.05<\mathrm{p}<0.1)$ neutrophils and lymphocyte infiltration in BALF, showing significantly lower lymphocytes in the TRE 2-mg group.

As shown in figure 3, IL-4, IL-5 and eotaxin levels in BALF were significantly reduced in all TRE and prednisolone groups. In addition, the $\mathrm{PGE}_{2}$ level in BALF was 
Fig. 4. Lung histology from control and TRE-supplemented mice sensitized and challenged with OVA. Microscopic images were made with a Leica DMR microscope at a magnification of 100 , and images are representative of the experimental group. Lung histology from PBS-sensitized mice is also shown for comparison.
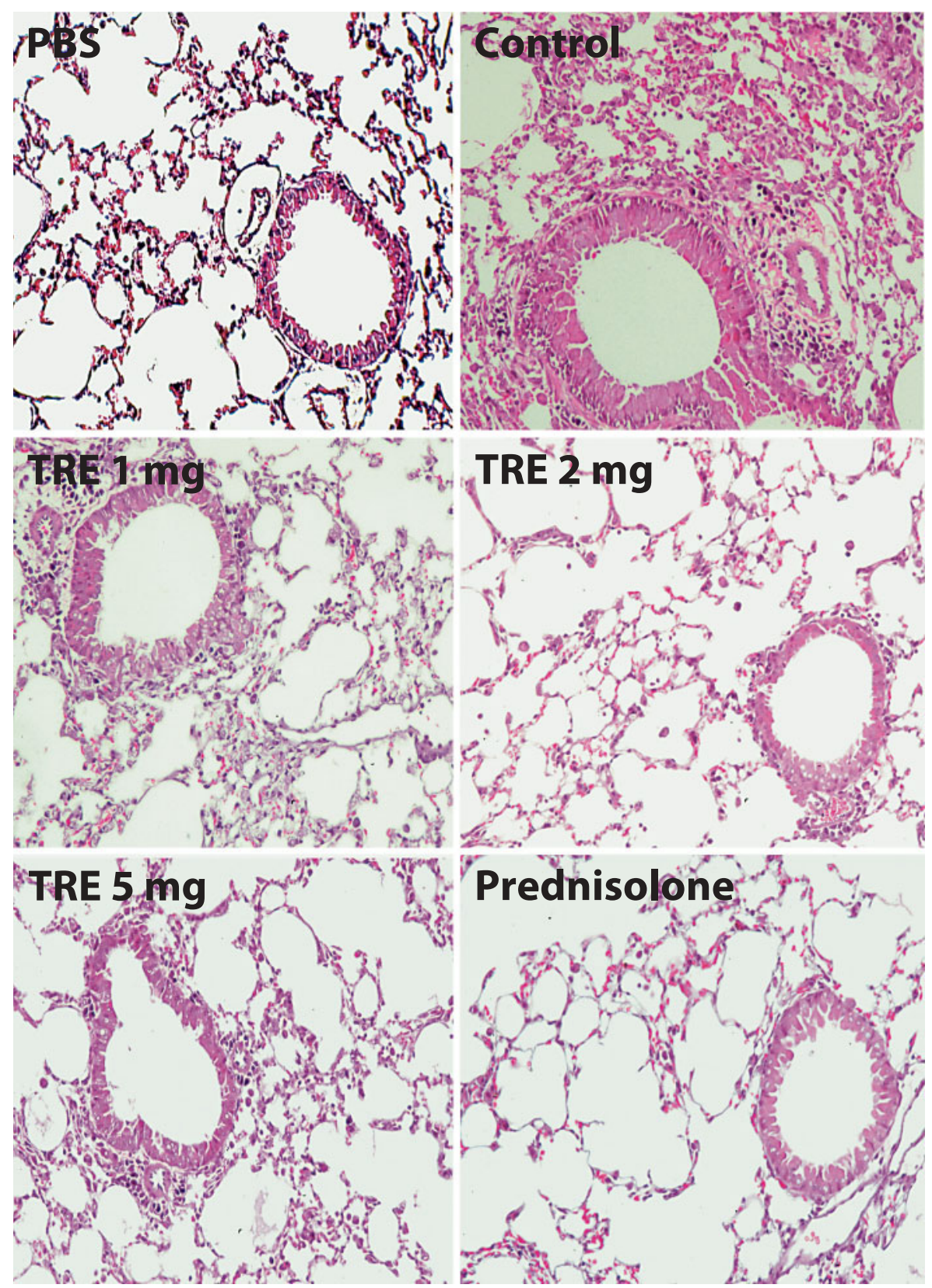

greatly reduced by prednisolone treatment and only significantly reduced in the TRE 1-mg group. It suggests that TRE possesses a similar anti-inflammatory effect with prednisolone that is commonly used for the treatment of asthma. The lung histology shown in figure 4 indicated that under OVA sensitization and challenge, many cells infiltrated around the bronchial and lung alveoli in the control group. However, less inflammatory cell infiltration in the lungs from the TRE and prednisolone treatment groups was noted.
Effects of TRE on Splenocyte Numbers and Th2 Cell

Responses

As shown in table 2, total splenocytes were not significantly affected by TRE supplement, but were significantly reduced in the prednisolone compared with the control group. However, secretion of IL-5, one of the Th2 cytokines, from OVA-stimulated splenocytes was significantly lower by both TRE and prednisolone treatment (table 2). Another Th2 cytokine, IL-4, also tended to be lower $(0.05<\mathrm{p}<0.1)$ in the TRE 1 -mg and prednisolone 
groups. Secretion of Th1 cytokine, IL-2 and IFN- $\gamma$ was not significantly affected by TRE treatment (data not shown). The spontaneous cytokine secretion was almost undetectable in this study. Prednisolone treatment significantly decreased OVA-stimulated IFN- $\gamma$ and ConAstimulated IL-2 production, which was not affected by TRE supplement (data not shown).

\section{Effects of TRE on OVA-Specific Antibodies}

Serum OVA-specific IgE, IgG1 and IgG2a antibody levels are shown in table 3. The OVA-specific IgE titers were not significantly decreased by TRE and prednisolone treatment for 7 days, at day 49 of the experimental procedure. OVA-specific IgG1 levels were significantly lower in the TRE 1-mg, TRE 5-mg and prednisolone groups. The IgG2a levels were also decreased by prednisolone treatment, but not by TRE treatment.

\section{Discussion}

It has been demonstrated that triterpenoid extracts from G. lucidum decrease histamine release from rat peritoneal mast cells in vitro [10]. Our report is the first study on the effect of triterpenoid extract of G. tsugae on allergic asthma in vivo. Mice were sensitized and challenged with OVA to induce the typical asthmatic symptoms, such as AHR and eosinophilic airway inflammation. Steroids, such as prednisolone, shown to reduce eosinophilia that was induced by IL-5 challenge in the airway of Brown Norway rats [15], was used as the positive therapeutic reagent to evaluate the effect on allergic immune responses by dietary treatment.

In this study, prednisolone treatment significantly decreased AHR and the inflammatory mediators, such as IL-4, IL-5, PGE 2 and eotaxin secretion. Similarly, TRE treatment also decreased AHR, cell recruitment in BALF and the lung, and inflammatory mediators, IL-4, IL-5 and eotaxin in BALF, which alleviate allergic airway inflammation. Several reports have suggested that IL-5 and eotaxin both play essential roles in the recruitment of eosinophils to the inflammatory sites $[16,17]$. Also, IL-4 plays a role in the induction of endothelial vascular cell adhesion molecule-1 expression, which leads to preferential eosinophil recruitment [18]. Blockade of IL-4 receptor or lack of IL-4 receptor $\alpha$ chain significantly reduced AHR induced by antigen sensitization, suggesting that the IL-4 receptor is necessary for in vivo development of antigen-induced AHR $[19,20]$. We also found that BALF eosinophilia significantly correlated with the amounts of
Table 2. Effects of triterpenoid supplementation on splenocyte counts and cytokine secretion by OVA-stimulated splenocytes of OVA-sensitized and challenged BALB/c mice after 2 weeks of feeding

\begin{tabular}{lccc}
\hline \multirow{2}{*}{$\begin{array}{l}\text { Groups } \\
\text { cytes, } \times 10^{7}\end{array}$} & \multicolumn{2}{l}{ Th2 cytokine, pg/ml } \\
\cline { 3 - 4 } & & IL-4 & IL-5 \\
\hline Control & $4.57 \pm 1.76$ & $12.50 \pm 1.82$ & $4.30 \pm 1.76$ \\
TRE 1 mg & $4.72 \pm 2.55$ & $9.90 \pm 3.25^{* *}$ & $2.58 \pm 1.65^{*}$ \\
TRE 2 mg & $5.29 \pm 2.51$ & $13.48 \pm 3.02$ & $2.49 \pm 1.08^{*}$ \\
TRE 5 mg & $5.30 \pm 2.76$ & $10.43 \pm 3.72$ & $2.61 \pm 1.12^{*}$ \\
Prednisolone & $0.75 \pm 0.53^{*}$ & $9.18 \pm 2.13^{* *}$ & $2.10 \pm 0.59^{*}$ \\
\hline
\end{tabular}

The $5 \times 10^{6}$ cells $/ \mathrm{ml}$ splenocytes were cultured with the medium described earlier in the absence or presence of OVA $(25 \mu \mathrm{g} /$ $\mathrm{ml}$ ) for $48 \mathrm{~h}$. IL- 4 and IL-5 levels were determined by the ELISA method.

${ }^{*} \mathrm{p}<0.05$; ${ }^{*} 0.05<\mathrm{p}<0.1$; significantly different from the control group (log-transformed data analyzed by Student's t test; $\mathrm{n}=8-10$, mean $\pm \mathrm{SD})$.

Table 3. Effects of triterpenoid supplementation on serum OVAspecific antibody levels of OVA-sensitized and challenged $\mathrm{BALB} / \mathrm{c}$ mice after 2 weeks of feeding

\begin{tabular}{llll}
\hline & \multicolumn{3}{l}{ OVA-specific antibody titer, ELISA units } \\
\cline { 2 - 4 } & IgE & IgG1 & IgG2a \\
\hline Control & $0.51 \pm 0.24$ & $1.29 \pm 0.36$ & $1.10 \pm 0.59$ \\
TRE 1 mg & $0.39 \pm 0.10$ & $0.98 \pm 0.38^{*}$ & $1.19 \pm 0.59$ \\
TRE 2 mg & $0.49 \pm 0.15$ & $1.07 \pm 0.25$ & $1.60 \pm 0.72$ \\
TRE 5 mg & $0.49 \pm 0.19$ & $0.98 \pm 0.39^{*}$ & $1.06 \pm 0.74$ \\
Prednisolone & $0.40 \pm 0.14$ & $0.61 \pm 0.17^{*}$ & $0.63 \pm 0.39^{* *}$ \\
\hline
\end{tabular}

Sera were collected for antibody analysis on day 49 . OVA-specific IgE, IgG1 and IgG2a levels were determined by ELISA.

${ }^{*} \mathrm{p}<0.05$; significantly different from the control group ( $\mathrm{n}=$ $8-10$, mean \pm SD).

** Significantly different from the control group by log-transformed data.

IL-5 $(r=0.61)$ and eotaxin $(r=0.70)$ in BALF, and IL-4 production in BALF significantly correlated with AHR $(r=0.33)$ in this study. Our results indicated that the triterpenoids of $G$. tsugae might alleviate AHR via reducing IL-4, eotaxin and IL-5 levels in BALF, thus decreasing eosinophilic infiltration in the airway.

Although some studies showed that an amplified AHR response was not directly correlated with the recruitment 
of eosinophils in eosinophil-deficient mice or in several cytokine-deficient mice administered with IL-13 [21, 20], the researchers still suggested a close relationship between eosinophils, IL-5 and IL-13 in the mechanisms causing AHR in the allergic lung, and also the contribution of eosinophils in subepithelial collagen deposition and the increases in airway smooth muscle. Despite that the contribution of eosinophils to lung dysfunction has been controversial, the eosinophil is thought to be the critical cell involved in asthma pathogenesis. MacKenzie et al. [22] have demonstrated that eosinophils modulate allergic inflammation by amplifying Th2 cell responses. In addition, it has been reported that epithelial damage of the trachea is associated with mobilization of neutrophils or eosinophils in the airway lumen during acute exacerbations of asthma [23]. The number of airway neutrophils increases during the late-phase response after an allergen challenge [24]. Neutrophils are also a potential source of inflammatory mediators in allergic asthma [25]. Our data demonstrated decreased eosinophils and neutrophil infiltration in BALF, especially eosinophilia, of TRE-supplemented groups (table 1). Consistently, lung histology also showed less inflammatory cell infiltration in the lungs of TRE-supplemented mice (fig. 4). Our data demonstrated that triterpenoid supplementation should suppress cellular inflammation in allergic asthma.

In addition, eicosanoids have been linked with inflammatory diseases, such as cardiovascular disease and asthma [26]. An increased $\mathrm{PGE}_{2}$ level was demonstrated to aggravate the inflammatory process [27]. In the present study, prednisolone, an anti-inflammatory drug, dramatically decreased $\mathrm{PGE}_{2}$ production in BALF of OVAsensitized and challenged mice. $\mathrm{PGE}_{2}$ levels were lower in BALF of TRE-supplemented mice, though only the lowdose group (1 mg/day) reached a statistical significance.

$\mathrm{PGE}_{2}$ inhibits the production of Th1 cytokines but not of Th2 cytokines [28]. It has been reported that $\mathrm{PGE}_{2}$ inhibited IL-12 synthesis, which is a critical cytokine in Th1 development [29]. T cell responses in allergic asthma are known to be Th2 cell dominant. Th2 cell cytokines, such as IL-4 and IL-5, have been reported to play crucial roles in the late phase of allergic disease [30]. Hence, blocking Th2-derived responses or increasing the function of Th1 cells can be regarded as an important target for the treatments of allergic asthma. A recent report showed that the Chinese herbal medicine FAHF-2, a G. lucidum-rich formula, suppressed IL-4, IL-5 and IL-13 production from antigen-stimulated splenocytes [5]. Our data demonstrated that IL-4 and IL-5 levels significantly decreased in BALF of TRE-supplemented and prednisolone groups.
Further, the effect on splenocytes by TRE supplement was also investigated. The secretions of Th1 cytokines, such as IL-2 and IFN- $\gamma$, from OVA-stimulated splenocytes were not significantly affected by TRE supplement, but suppressed by prednisolone (data not shown). However, the secretion of one of the Th2 cytokines, IL-5, was significantly lower in TRE- or prednisolone-treated mice. Another Th2 cytokine, IL-4, only tended to be lower in the TRE 1-mg and prednisolone groups $(0.05<\mathrm{p}<0.1)$. Cytokines such as IL-5 derived from Th2 cells were found to induce eosinophilia, which is critical in the late stage of inflammation of asthma [31]. Therefore, suppression of IL- 5 secretion by splenocytes might contribute to less eosinophil infiltration and lower levels of inflammatory mediators in BALF and lung tissue in the present study.

Both in vivo and in vitro evidence suggested that $\mathrm{cy}-$ tokines like IL-4 are important for the immunoglobulin class switch from IgM to IgE [32, 33]. Antigen-specific $\mathrm{IgE}$ is essential for the development of allergic reactions. It starts the cascade of allergic responses through crosslinking with antigens. Several therapies have been designed to reduce the a mount or effect of $\operatorname{IgE}$, and blocking the binding of IgE to its receptors is the most effective strategy for allergic diseases [34]. In the present study, the OVA-specific IgE levels were not significantly lower in the TRE and prednisolone groups. It might be explained by the suppression of OVA-stimulated IL-4 secretion from splenocytes of OVA-sensitized and challenged mice which was not intense enough to decrease IgE significantly, though Th2-related antigen-specific IgG1 antibody levels were significantly lower in the TRE 1-mg, TRE 5-mg and prednisolone groups. Antigen-specific IgG1 also plays a critical role in allergic responses. In addition to the activation of mast cells by IgE binding via the FceRI receptor, which initiates allergic response, antigen-specific IgG1 may also activate mast cells through the binding of the Fc $\gamma$ RIII receptor on the surface of murine mast cells [35]. It has been demonstrated that IgG1 increased AHR after airway challenge [36]. One study also showed that Dermatophagoides pteronyssinus group 2 specific IgG1 was significantly decreased while IgG2a production was increased in $D$. pteronyssinus group 2 intraperitoneally sensitized mice fed with G. lucidum [37]. Therefore, the IgG1 lowering effect of Ganoderma may be beneficial in antigen-specific allergic responses.

Corticosteroids are the most common and powerful anti-inflammatory drugs used to treat asthma for a long time. Prednisolone treatment is known to decrease AHR, eosinophilia in the lung, serum IgE levels, and IL-2 and IL-4 production by ConA-stimulated splenocytes [38, 
39]. However, the side effects of corticosteroids may cause problems. In the present study, prednisolone treatment significantly decreased the relative spleen and lung weight of allergic mice, but TRE did not (data not shown). Prednisolone did not only suppress Th2 responses but also total immune cell population, Th1 responses, such as IL-2 and IFN- $\gamma$ secretions by OVA- and ConA-stimulated splenocytes (data not shown), and OVA-specific IgG2a production. These might be due to the induction of $\mathrm{T}$ cell apoptosis by corticosteroids [40]. Unlike prednisolone, TRE did not affect or decrease spleen cell numbers. It has been known that the mechanisms of prednisolone treatment for allergic asthma suppress immune responses, which might pose a risk of infection. The TRE supplement decreased airway inflammation and Th2 respons- es, but did not suppress Th1 responses in this study. In addition, the suppressive effect of TRE was dose independent, which was inconsistent with the previous study when a whole extract of fruit bodies of $G$. tsugae was tested [1].

In conclusion, Th2 responses such as IL-5 secreted from OVA-stimulated splenocytes, serum OVA-specific IgG1 levels, eosinophil infiltration and secretions of IL-4, IL-5 and eotaxin in BALF, and thus AHR, were significantly suppressed in OVA-sensitized and challenged mice supplemented with TRE of G. tsugae. These results suggest that triterpenoids may have possible therapeutic applications in allergic asthma. The mechanism of triterpenoids of G. tsugae in regulation of cytokine production is the subject of ongoing research.

\section{References}

1 Lin JY, Chen ML, Chiang BL, Lin BF: Ganoderma tsugae supplementation alleviates bronchoalveolar inflammation in an airway sensitization and challenge mouse model. Int Immunopharmacol 2006;6:241-251.

-2 O’Byrne PM, Inman MD, Adelroth E: Reassessing the Th2 cytokine basis of asthma. Trends Pharmacol Sci 2004;25:244-248.

-3 Li XM, Huang CK, Zhang TF, Teper AA, Srivastava K, Schofield BH, Sampson HA: The Chinese herbal medicine formula MSSM-002 suppresses allergic airway hyperreactivity and modulates Th1/Th2 responses in a murine model of allergic asthma. J Allergy Clin Immunol 2002; 106: 660-668.

-4 Srivastava K, Teper AA, Zhang TF, Li S, Walsh MJ, Huang CK, Kattan M, Schofield BH, Sampson HA, Li XM: Immunomodulatory effect of the antiasthma Chinese herbal formula MSSM-002 on Th2 cells. J Allergy Clin Immunol 2004;113:268-276.

5 Srivastava K, Kattan JD, Zou ZM, Li JH, Zhang L, Wallenstein S, Goldfarb J, Sampson HA, Li XM: The Chinese herbal medicine formula FAHF-2 completely blocks anaphylactic reactions in a murine model of peanut allergy. J Allergy Clin Immunol 2005; 115:171-178.

-6 Shiao MS: Natural products of the medicinal fungus Ganoderma lucidum: occurrence, biological activities, and pharmacological functions. Chem Rec 2003;3:172-180.

7 Wang G, Zhang J, Mizuno T, Zhuang C, Ito $\mathrm{H}$, Mayuzumi H, Okamoto H, Li J: Antitumor active polysaccharides from the Chinese mushroom Songshan lingzhi, the fruiting body of Ganoderma tsugae. Biosci Biotechnol Biochem 1993;57:894-900.
8 Peng Y, Zhang L, Zeng F, Kennedy JF: Structure and antitumor activities of the watersoluble polysaccharides from Ganoderma tsugae mycelium. Carbohydr Polym 2005; 59:385-392.

9 Chen ML, Lin JY, Lin BF: The immunomodulatory effects of Ganoderma tsugae supplementation on immune responses of BALB/c mice. Taiwan J Agric Chem Food Sci, in press.

10 Kohda H, Tokumoto W, Sakamoto K, Fujii M, Hirai Y, Yamasaki K, Komoda Y, Nakamura H, Ishihara S, Uchida M: The biologically active constituents of Ganoderma lucidum (Fr) Karst. Histamine release-inhibitory triterpenes. Chem Pharm Bull (Tokyo) 1985;33:1367-1374.

-11 Chen DH, Shiou WY, Wang KC, Huang SY, Shie YT, Tsai CM, Shie JF, Chen KD: Chemotaxonomy of triterpenoid pattern of HPLC of Ganoderma lucidum and Ganoderma tsugae. J Chin Chem Soc 1999;46:47-51.

12 Chen DH, Chen WKD: Determination of ganoderic acids in triterpenoid constituents of Ganoderma tsugae. J Food Drug Anal 2003;11:195-201.

13 Lin JY, Lin BF: Effects of weekly vs bi-weekly ovalbumin sensitization protocols in ICR mice. Food Sci Agric Chem 2000;2:28-34.

14 Hamelmann E, Schwarze J, Takeda K, Oshiba A, Larsen GL, Irvin GG, Gelfand EW: Noninvasive measurement of airway responsiveness in allergic mice using barometric plethysmography. Am J Respir Crit Care Med 1997;156:766-775.

15 Takizawa T, Kawaka N, Tanaka H, Nagai H: Effect of antiallergic drugs on interleukin 5induced eosinophil infiltration of rat airways. Biol Pharm Bull 2002;25:318-322.
16 Menzies-Gow A, Ying S, Sabroe I, Stubbs VL, Soler D, Williams TJ, Kay AB: Eotaxin (CCL11) and eotaxin-2 (CCL24) induce recruitment of eosinophils, basophils, neutrophils, and macrophages as well as features of early- and late-phase allergic reactions following cutaneous injection in human atopic and nonatopic volunteers. J Immunol 2002; 169:2712-2718

17 Lampinen M, Rak S, Venge P: The role of interleukin-5, interleukin-8 and RANTES in the chemotactic attraction of eosinophils to the allergic lung. Clin Exp Allergy 1999;29: 314-322.

18 Schleimer RP, Sterbinsky SA, Kaiser J, Bickel CA, Klunk DA, Tomioka K, Newman W, Luscinskas FW, Gimbrone MA Jr, McIntyre BW, Bochner BS: IL-4 induces adherence of human eosinophils and basophils but not neutrophils to endothelium. Association with expression of VCAM-1. J Immunol 1992;148:1086-1092.

19 Gavett SH, O'Hearn DJ, Karp CL, Patel EA, Schofield BH, Finkelman FD, Wills-Karp M: Interleukin-4 receptor blockade prevents airway responses induced by antigen challenge in mice. Am J Physiol 1997;272:L253L261.

20 Yang M, Hogan SP, Henry PJ, Matthaei KI, McKenzie AN, Young IG, Rothenberg ME, Foster PS: Interleukin-13 mediates airways hyperreactivity through the IL-4 receptoralpha chain and STAT- 6 independently of IL-5 and eotaxin. Am J Respir Cell Mol Biol 2001;25:522-530.

21 Humbles AA, Lloyd CM, McMillan SJ, Friend DS, Xanthou G, McKenna EE, Ghiran S, Gerard NP, Yu C, Orkin SH, Gerard C: A critical role for eosinophils in allergic airways remodeling. Science 2004;305:17761779. 
22 MacKenzie JR, Mattes J, Dent LA, Foster PS: Eosinophils promote allergic disease of the lung by regulating CD4+ Th2 lymphocyte function. J Immunol 2001;167:3146-3155

$\checkmark 23$ Yoshihara S, Yamada Y, Abe T, Lindén A, Arisaka O: Association of epithelial damage and signs of neutrophil mobilization in the airways during acute exacerbations of paediatric asthma. Clin Exp Immunol 2006;144: 212-216.

-24 Montefort S, Gratziou C, Goulding D, Polosa R, Haskard DO, Howarth PH, Holgate ST, Carroll MP: Bronchial biopsy evidence for leukocyte infiltration and upregulation of leukocyte-endothelial cell adhesion molecules $6 \mathrm{~h}$ after local allergen challenge of sensitized asthmatic airways. J Clin Invest 1994; 93:1411-1421.

-25 Hampton MB, Kettle AJ, Winterbourn CC: Inside the neutrophil phagosome: oxidants, myeloperoxidase, and bacterial killing. Blood 1998;92:3007-3017.

26 Goetzl EJ, An S, Smith WL: Specificity of expression and effects of eicosanoid mediators in normal physiology and human diseases. FASEB J 1995;9:1051-1058.

$\checkmark 27$ Roper RL, Brown DM, Phipps RP: Prostaglandin $\mathrm{E}_{2}$ promotes $\mathrm{B}$ lymphocyte Ig isotype switching to IgE. J Immunol 1995;154: 162-170.

28 Betz M, Fox BS: Prostaglandin $E_{2}$ inhibits production of Th1 lymphokines but not of Th2 lymphokines. J Immunol 1991;146:108113.
29 van der Pouw Kraan TC, Boeije LC, Smeenk RJ, Wijdenes J, Aarden LA: Prostaglandin- $\mathrm{E}_{2}$ is a potent inhibitor of human interleukin 12 production. J Exp Med 1995;181:775-779.

30 Larche M, Robinson D S, Kay AB: The role of T lymphocytes in the pathogenesis of asthma. J Allergy Clin Immunol 2003;111:450 463.

31 Marone G: Asthma: recent advances. Immunol Today 1998;19:5-9.

32 Romagnani S: Regulation and deregulation of human IgE synthesis. Immunol Today 1990;11:316-321.

33 Chretien I, Pene J, Briere F, Malefijt RDW, Rousset JED: Regulation of human IgE synthesis. 1. Human IgE synthesis in vitro is determined by the reciprocal antagonistic effects of interleukin- 4 and interferon- $\gamma$. Eur J Immunol 1990;20:243-251.

34 Leung DYM, Sampson HA, Yunginger JW, Burks AW, Schneider LC, Wortel CH, Davis FM, Hyun JD, Shanahan WR: Effects of antiIgE therapy in patients with peanut allergy. N Engl J Med 2003;348:986-993.

35 Miyajima I, Dombrowicz D, Martin TR, Ravetch JV, Kinet JP, Galli SJ: Systemic anaphylaxis in the mouse can be mediated largely through IgG1 and Fc $\gamma$ RIII. Assessment of the cardiopulmonary changes, mast cell degranulation, and death associated with active or IgE- or IgG1-dependent passive anaphylaxis. J Clin Invest 1997;99:901-914.

36 Oshiba A, Hamelmann E, Takeda K, Bradley KL, Loader JE, Larsen GL, Gelfand EW: Passive transfer of immediate hypersensitivity and airway hyper-responsiveness by allergen-specific immunoglobulin (Ig) E and IgG1 in mice. J Clin Invest 1996;97:13981408 .
37 Liu YH, Tsai CF, Kao MC, Lai YL, Tsai JJ: Effectiveness of Dp2 nasal therapy for Dp2-induced airway inflammation in mice: using oral Ganoderma lucidum as an immunomodulator. J Microbiol Immunol Infect 2003;36:236-242.

38 Fukakusa M, Bergeron C, Tulic MK, Fiset PO, Dewachi OA, Laviolette M, Hamid Q, Chakir J: Oral corticosteroids decrease eosinophil and CC chemokine expression but increase neutrophil, IL-8, and IFN $\gamma$-inducible protein 10 expression in asthmatic airway mucosa. J Allergy Clin Immunol 2005; 115:280-286.

39 Mimura T, Shinozaki Y, Kawasaki H, Iwamura H: JTP-27536 [(+)-1,3-dihydroxy2-hydroxymethylpropyl-2-ammonium 2[(R)-3-cyclo-hexyl-1-phenylpropyl]-1,3-dioxo-2,3-dihydro-1H-isoindole-5-carboxylate monohydrate], a novel inhibitor of immunoglobulins and interleukin-5 with anti-inflammatory properties in mouse allergic dermatitis model. J Pharmacol Exp Ther 2005;314:293-301.

40 Marchetti MC, Marco BD, Santini MC, Bartoli A, Delfino DV, Riccardi C: Dexamethasone-induced thymocytes apoptosis requires glucocorticoid receptor nuclear translocation but not mitochondrial membrane potential transition. Toxicol Lett 2003;139: 175-180. 